\title{
The Low Cost, High Performance Material for Automotive Application
}

\author{
Sangilimuthukumar J, Winowlin Jappes J T, Siva I, Brintha N C
}

\begin{abstract}
Recently, composite materials are used in various automotive applications. The reasons for composite materials are low weight and can withstand high strength. The present work focuses on the preparation and characterization of some advanced Fiber metal laminate (FML) like $A l / B F$ with epoxy, $A l / C F$ with epoxy, Al/GF with epoxy and its automotive application. Fiber metal laminate is the arrangement of metal fiber, resin in required stacking order. The required fiber metal laminate was fabricated using compression moulding process and the samples were subjected to wide range of mechanical and thermo mechanical characterizations such as tensile strength, impact, erosion wear and flammability test respectively. All the tests are done as per ASTM standards. The applicability and replaceability of the material with conventional automotive materials were studied and results were tabulated.
\end{abstract}

Keywords : FML, Aluminium (Al), Basalt fiber (BF), Glass Fiber (GF), Ceramic Foam (CF), compression moulding, mechanical, thermo-mechanical properties, automotive application.

\section{INTRODUCTION}

$\mathrm{C}$ omposite materials made up of two or more suitable materials in order to improve the mechanical properties and other related constraints, improves the performance and reduces the manufacturing cost. Most of the common composite fibers are glass, carbon and organic and some of the dedicated applications were used with boron, silicon carbide and alumina those are commonly termed as ceramics and ceramic based fibers. Several researches were undertaken with natural fibers, synthetic fibers, glass and carbon fibers as reinforcement materials in order to find the suitability for automotive, aerospace applications [1]. Natural fiber composites are credited with good specific strength, stiffness and low density however lacks in durability of untreated and results in swelling since the name has high moisture absorption property [2]. The usage of synthetic fibers was restricted as the consciousness towards conserving the environmental has been considerably increased. Even though the consumption of synthetic fibers improves the stiffness

Revised Manuscript Received on December 15, 2019

* Correspondence Author

Sangilimuthukumar J, Centre for Composite Materials, Department of Mechanical Engineering, Kalasalingam Academy of Research \& Education, Virudhunagar, Tamilnadu, India Email: sangili112140@gmail.com.

Winowlin Jappes J T*, Centre for Composite Materials, Department of Mechanical Engineering, Kalasalingam Academy of Research \& Education, Virudhunagar, Tamilnadu, India Email: winowlin@klu.ac.in.

Siva I, Centre for Composite Materials, Department of Mechanical Engineering, Kalasalingam Academy of Research \& Education, Virudhunagar, Tamilnadu, India, Email: isiva@klu.ac.in.

Brintha N C, Department of Computer Science and Engineering, Kalasalingam Academy of Research and Education, Virudhunagar, Tamilnadu, India. Email: brinthachris2k@gmail.com. and strength properties. The recyclability and biodegradability hinder the adoptability of the synthetic fibers [3-6]. The advancement in fiber reinforced polymer composite laminates with glass and carbon fiber as reinforcement are widely used for many engineering applications such as aerospace, automotive, oil and marine industries owing to their physical as well as mechanical properties. Fiber glass was first used as an insulation material for thermal, electrical and acoustic applications. It is also used for wide variety of applications as it has good chemical resistance, resists water attacks on the other hand lacks in mechanical properties. Carbon fibres irrespective of having wide potential properties such as resistance to high temperature, high strength, high stiffness to weight ratio, good corrosion resistance which is very expense and hence hinders its use in some of the commercial applications. On the other hand, sophisticated applications in the aerospace industries now greatly relies on carbon-based materials. These provoking hindrances are greatly overcome by adapting fiber metal laminates as a potential replacement for these conventional fibres [7]. FML finds various application in the field of aircraft industries owing to its rich mechanical properties. FML is to have various layers of metals and fibers which are stick together by means of adhesive bonding using resin normally epoxy. Aluminium alloys find its place in FML due to its light weight. Beside $\mathrm{Al}$, other metal such as magnesium, titanium, nitinol and steel are also used [8-10].

\section{EXPERIMENTAL DETAILS}

\section{A. Materials Used}

E-Glass fiber mat were purchased from G.V.R. Enterprises, Madurai, Tamilnadu. Ceramic foam was purchased from Covai Seenu and company Coimbatore, Tamilnadu. Basalt fiber mat were supplied by Sakthi Pvt. Ltd., Chennai, Tamilnadu. Epoxy resin of type (VBR8912) and hardner (VBR 1209) was used as the FML composites. Epoxy and hardner were purchased from Vasavibala Resins (P) Ltd., Chennai, Tamilnadu. A thin sheet of (thickness $0.4 \mathrm{~mm}$ ) Aluminium alloy Al2024 supplied by Covai metals, Tamilnadu.

\section{B. Fabication of Composites}

FML are fabricated using basalt fiber/epoxy with aluminium 2025 face sheet, E-Glass fiber/epoxy with aluminium 2025, Ceramic Foam/epoxy with aluminium 2025 face sheet face sheet the sequencing order of $\mathrm{Al} / \mathrm{BF} / \mathrm{Al} / \mathrm{BF} / \mathrm{Al}, \mathrm{Al} / \mathrm{GF} / \mathrm{Al} / \mathrm{GF} / \mathrm{Al}, \mathrm{Al} / \mathrm{CF} / \mathrm{Al}$ respectively. The dimension of the sample what we have to fabricate is 300 x 125 x $3 \mathrm{~mm}$. So, we have to cut the Aluminium sheet and basalt, glass, ceramic fibre as 
per the dimension what we required. The sample is fabricated using compression moulding machine, so it is necessary to prepare proper mould for the preparation of sample. The mould is consisting of three plates such as upper, middle, bottom $(300 \times 125 \times 3 \mathrm{~mm})$ of the plates. At the first wax have applied in the mould surface, the reason for this applied is easy to remove the plate from the mould die. After the preparation of the mould and raw material we have to prepare resin for the sample fabrication process. The resin is the combination of epoxy (VBR 8912) and hardner (VBR1209). The mixing ratio for the epoxy and hardner is $2: 1$. At last the bottom and middle part or mould is attached together, and the opposite corner of the mould is fixed with two bolts to arrest the slide movement of the plates. The sample have three layers of the aluminium and two layers of the fibers for arranged by the above mention sequence order. The resin has to be applied between each layer of the aluminium and fiber by without any air bubbles(gap) formation. After the applying and setting of all layer the top mould is have to be fixed. Then the mould is placed on the compression moulding machine and it have to be compressed at pressure of 150 $\mathrm{kgf} / \mathrm{cm} 3$. The casting is allowed to cure in the room temperature for about 5 to 6 hours. Now the mould is removed from the compression moulding machine and is cut into the required dimensions by abrasive water jet machining for various experiments tests.

\section{Tensile Strength}

The tensile test was conducted in Universal Testing Machine according to the ASTM D638 to evaluate the tensile strength of the specimen. The dimensions of the specimen are $200 \times 20 \times 3 \mathrm{~mm}$, respectively.

\section{Impact Test}

An impact test was conducted in Izod Charpy Testing machine according to the ASTM D256 to study the impact energy of the specimen. For this testing the sample is made up of dimension as $(65 \times 13 \times 3) \mathrm{mm}$.

\section{E. Erosion Test}

An erosion wear tests of the FML composites were performed in air jet erosion tester to measured for calculating erosion rate of the specimen. The sample size of the specimen according to the ASTMG76 standard dimension is $25 \times 25 \times 5$ $\mathrm{mm}$.

\section{F. Flammability test}

Flammability test was in done in UL94 prolific Flammability tester. Flammability is the ability of a substance to burn or ignite, causing fire or combustion. The standard size of the specimen is $167 \times 13 \times 3 \mathrm{~mm}$.

\section{RESULTS AND DISCUSSION}

\section{A. Effect on the tensile strength of FML (Al/BF/GF/CF) Composites}

Figure 1 shows the tensile strength of the FML (Al/BF/GF/CF) composites which carried out the Universal Testing Machine. It is observed from the figure that the maximum tensile strength of the material is observed at 85.26 MPa for Aluminium/Basalt fibre mat combination. Tensile strength of the Aluminium/Basalt fibre mat combination
(85.26 MPa) was greater than the Alu/Ceramic Foam (40.82 $\mathrm{MPa}$ ) and Alu/Glass fiber mat (64.97 MPa), combinations. The Alu/Glass fiber mat (64.97 MPa), combination of tensile strength is higher than the Alu/Ceramic Foam (40.82 MPa).

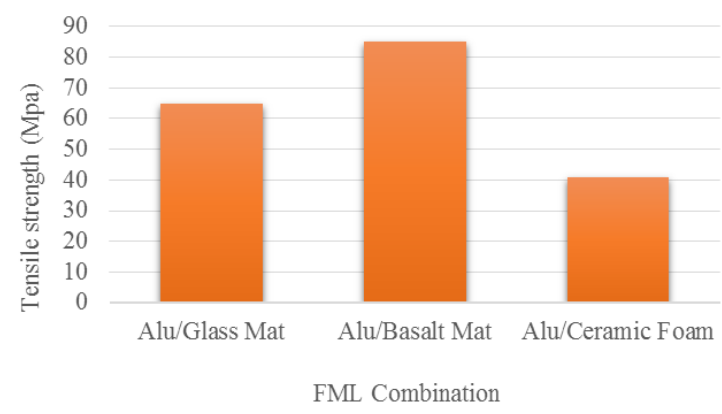

Fig. 1: Tensile strength on FML (Al/BF/GF/CF) Composites

\section{B. Effect on the Impact strength of FML (Al/BF/GF/CF) Composites}

Figure 2 shows the Impact strength of the FML (Al/BF/GF/CF) composites which carried out the Izod Charpy Impact tester. The impact strength of the Alu/Basalt, Alu/Glass and Alu/Ceramic combination of FML composite is 21,18 and $17 \mathrm{~J} / \mathrm{m}$ respectively. The Alu/Basalt $(21 \mathrm{~J} / \mathrm{m})$ combination impact strength is greater than the Alu/Ceramic Foam $(17 \mathrm{~J} / \mathrm{m})$ and Alu/Glass fiber mat $(18 \mathrm{~J} / \mathrm{m})$, combinations. The impact strength of Alu/Ceramic $(17 \mathrm{~J} / \mathrm{m})$ combination is lesser than the Alu/Basalt $(21 \mathrm{~J} / \mathrm{m})$ combination and Alu/Glass fiber mat $(18 \mathrm{~J} / \mathrm{m})$, combinations. Thus, the Alu/Basalt $(21 \mathrm{~J} / \mathrm{m})$ combination is greater impact properties of the sample.

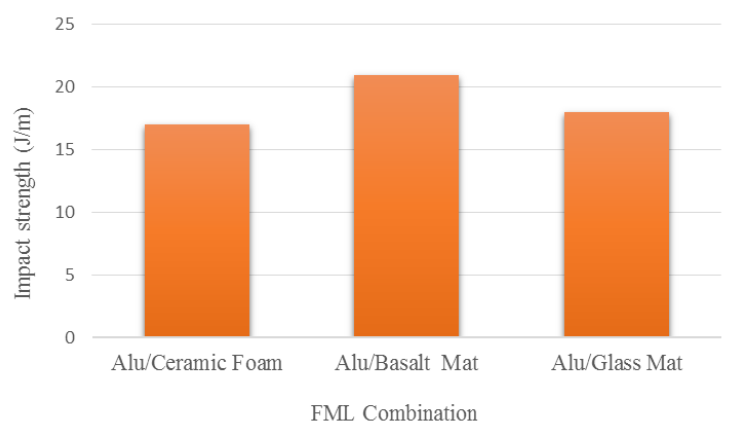

Fig. 2: Impact strength on FML (Al/BF/GF/CF) Composites

\section{Effect on the erosion test of Al/GF FML composite and GF composite}

An erosion wear is the damaging, gradual removal of material at solid surfaces. Erosion test was conducted in Air jet erosion tester according to the ASTM G76 standards. It was conducted by the input response such as impingement angle $\left(90^{\circ}\right)$, pressure (1bar), discharge $(3.3 \mathrm{~g} / \mathrm{m})$, and exposure time $(10,20,30,40 \mathrm{~min})$. Erodent particle was fixed as alumina powder with average particle size of $80 \mu \mathrm{m}$. The standoff distance i.e. the distance between the nozzle tip and the target material was also fixed at $10 \mathrm{~mm}$ and the experiment was conducted at room temperature. In this process the weight loss for Al/GF FML composite and GF composite was measured for calculating the erosion rate for the required specimen. The 
following formula is used to measured for calculating the erosion rate. Erosion Rate $(\mathrm{g} / \mathrm{g})=$ Weight Loss/Discharge $\mathrm{x}$ Time. Figure $3 \& 4$ shows the effect of erosion process variable time and erosion rate in Al/GF FML, GF composites respectively. It is observed that $\mathrm{Al} / \mathrm{GF}$ FML composite samples possess reduced mass loss. The experimental results were analysed from figure Al/GF FML composite had shown the better erosion resistive property. The erosion rates get increased in $\mathrm{Al} / \mathrm{GF} \mathrm{FML}$, when the time varies from lower(10min) to higher (20min). The GF composites the mass loss increases with increase in time.

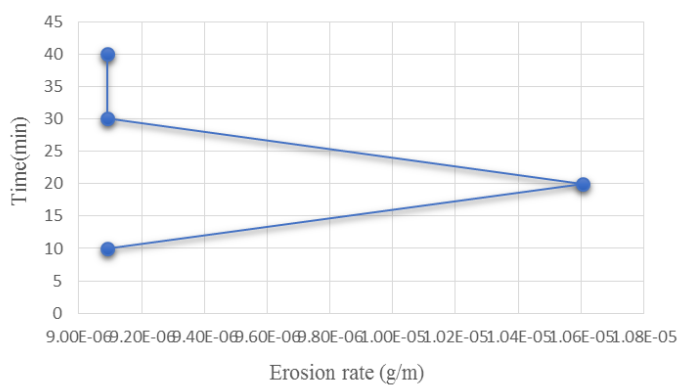

Figure 3 Effect of erosion process variable time and erosion rate in Al/GF FML composite

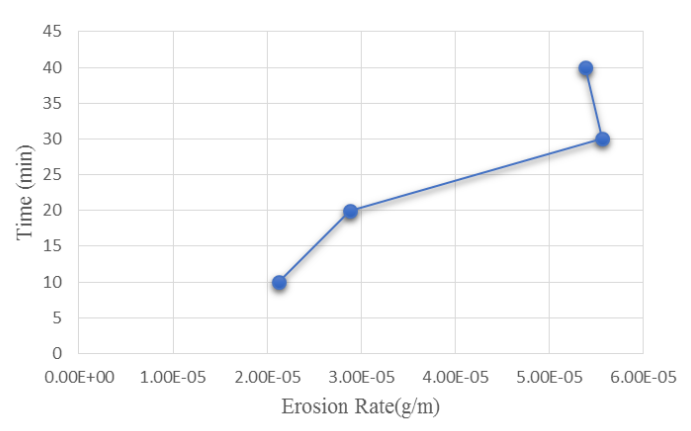

Figure 4 Effect of erosion process variable time and erosion rate in GF composite

\section{Flammability test of FML (Al/BF/GF/CF) Composites}

Flammability is the ability of a substance to burn or ignite, causing fire or combustion. The degree of difficulty required to cause the combustion of a substance is quantified though fire testing. Flammability test was done in UL94 prolific flammability tester. Table 1 shows the experimental table for flammability results in FML (Al/BF/GF/CF) Composites. The experimental results were analysed from Table 1 FML $(\mathrm{Al} / \mathrm{CF}$ ) combination is could withstand (Ignition of one min in $6 \mathrm{~mm}$ ) high flammability and could be used in fire resistivity. For other FML (Al/BF) and FML (Al/GF) combination is could withstand (Ignition of one min in $9 \mathrm{~mm}$ and $8 \mathrm{~mm}$ ) respectively. It can be observed that FML (Al/CF) composite samples possessed better fire resisting property.

Table I FML (Al/BF/GF/CF) Composite results obtained from flammability

\begin{tabular}{|l|l|l|l|l|l|}
\hline $\begin{array}{l}\text { Material } \\
\text { Sample }\end{array}$ & $\begin{array}{l}\text { Ignition } \\
\text { within 30 } \\
\text { sec }\end{array}$ & $\begin{array}{l}\text { Ignition } \\
\text { of one } \\
\text { min in } \\
\mathbf{m m}\end{array}$ & $\begin{array}{l}\text { Initial } \\
\text { mass (g) }\end{array}$ & $\begin{array}{l}\text { Final } \\
\text { mass (g) }\end{array}$ & $\begin{array}{l}\text { Weight } \\
\text { loss (g) }\end{array}$ \\
\hline AL/BF & $\begin{array}{l}\text { Not } \\
\text { ignited }\end{array}$ & 9 & 8.6794 & 8.6696 & 0.0098 \\
\hline
\end{tabular}

\begin{tabular}{|l|l|l|l|l|l|}
\hline AL/GF & $\begin{array}{l}\text { Not } \\
\text { ignited }\end{array}$ & 8 & 9.8143 & 9.8023 & 0.012 \\
\hline AL/CF & $\begin{array}{l}\text { Not } \\
\text { ignited }\end{array}$ & 6 & 14.5692 & 14.4786 & 0.0906 \\
\hline
\end{tabular}

\section{CONCLUSION}

From the mechanical and thermal properties conducted for the FML $(\mathrm{Al} / \mathrm{BF} / \mathrm{GF} / \mathrm{CF})$ composite the following conclusions were made,

The following observations were made by analyzing the results obtained from the various experiments performed. The mechanical properties and thermal properties of the developed FML were investigated and concluded that FML that were made of Aluminium and ceramic (Al/CF) combinations withstander flammability test for a short length were ignited within min. And that the combination made of FML (Al/BF) had a good tensile strength, and impact property. The combination of FML (Al/GF) composite material to attain good erosion resistance. Hence it could be concluded that the combination of FML (Al/CF) composite could withstand high flammability and could be used in automotive firewall application.

\section{REFERENCES}

1. Grigoriou, K., \& Mouritz, A. P. (2018). Modelling and testing of fibre metal laminates and their constituent materials in fire. Composite Structures, (May), 25-35.

2. Majerski, K., Surowska, B., \& Bienias, J. (2018). The comparison of effects of hygrothermal conditioning on mechanical properties of fibre metal laminates and fibre reinforced polymers. Composites Part B: Engineering, 142, 108-116.

3. Sharma, A. P., Khan, S. H., Kitey, R., \& Parameswaran, V. (2018). Effect of through thickness metal layer distribution on the low velocity impact response of fiber metal laminates. Polymer Testing, 65(October 2017), 301-312.

4. Aghamohammadi, H., Hosseini Abbandanak, S. N., Eslami-Farsani, R., \& Siadati, S. M. H. (2018). Effects of various aluminum surface treatments on the basalt fiber metal laminates interlaminar adhesion. International Journal of Adhesion and Adhesives, 84, 184-193.

5. Mohammed, I., Rahim, A., Talib, A., Thariq, M., Sultan, H., Jawaid, M., ... Saadon, S. (2018).com Mechanical Properties of Fibre-Metal Laminates Made of Natural/Synthetic Fibre Composites, 13(1), 2022-2034.

6. Trzepiecinski, T., Kubit, A., Kudelski, R., Kwolek, P., \& Obłój, A. (2018). Strength properties of aluminium/glass-fiber-reinforced laminate with additional epoxy adhesive film interlayer. International Journal of Adhesion and Adhesives, 85, 29-36.

7. Chandrasekar, M., \& Jawaid, M. (2016). An experimental review on the mechanical properties and hygrothermal behaviour of fibre metal laminates.

8. Patil, N. A., Mulik, S. S., Wangikar, K. S., \& Kulkarni, A. P. (2018). Characterization of Glass Laminate Aluminium Reinforced Epoxy- A Review. Procedia Manufacturing, 20, 554-562.

9. Surowska, B., \& Outline, C. (2017). Properties and characterization of fiber metal laminates.

10. Das, R., Chanda, A., Brechou, J., \& Banerjee, A. (2016). 17- Impact Behaviour of FML. Dynamic Deformation, Damaged and Fracture in Composites materials and structures.

\section{AUTHORS PROFILE}

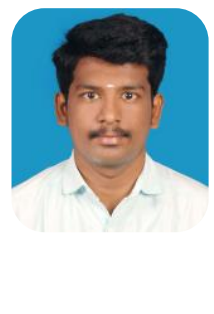

Mr. Sangilimuthukumar is obtained his bachelor degree in Automobile Engineering in 2017 and he completed his Master of Technology in Automotive system engineering in 2019 from Kalasalingam Academy of Research and Education, Tamil Nadu. 


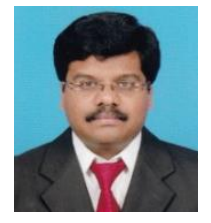

Dr. Winowlin Jappes J T graduated in 1997 from Manonmaniam Sunderanar University, India in Mechanical Engineering. In 1999, he has completed his masters in Production Engineering from Annamalai University. He completed his Ph.D degree in 2004 in the area of Composite Deposition at Indian Institute of Technology Madras, Chennai. He has completed three DST funded research projects and published more than 125 research articles which include 65 International Journal papers. Currently, he is working as Senior Professor in Kalasalingam University, India. His research interest includes high performance composite materials, machining of hard materials, optimization techniques, etc. At present, he is working as Professor and Dean, School of Automotive and Mechanical Engineering, Kalasalingam Academy of Research and Education, India.

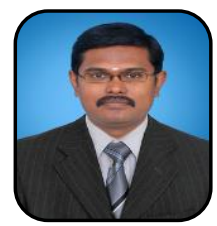

Dr. Siva I is obtained his Bachelors Degree in Mechanical Engineering in Mechanical Engineering from the Manonmaniam Sundaranar University, Tamilnadu/India (2002). In 2005 he acquired a Master's degree in Manufacturing Engineering by the Anna University, Tamilnadu/India and completed his $\mathrm{PhD}$ by the Department of Mechanical Engineering Kalasalingam University/India (2012). He is currently a Visiting Researcher at the Federal University of Rio Grande do Sul/Brazil in the Department of Materials Engineering. He is leading an Indo-Brazil Centre for Composite Materials in Kalasalingam University/India. His area of expertise is Engineering Materials with the focus on processing natural fibers, bio-composite, fiber surface modification, interfacial analysis, wear and vibrational analysis of natural fiber composites. He received a BJT-B fellowship from $\mathrm{CNPq} / \mathrm{Brazil}$. Recently, he received a collaboration project between India and Brazil through DST/India and CNPq/Brazil.

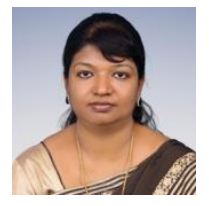

Dr. Brintha N C graduated in 2002 from Manonmaniam Sunderanar University, India. In 2006, she received her M.E Degree with distinction in Computer Science and Engineering from A.K.C.E, Anna University, Chennai. She completed her P.hd degree in 2018 in the area of Cloud Manufacturing under Anna University, Chennai. Currently, she is working as Associate professor/ CSE in Kalasalingam Academy of Research and Education, India. Her research interests include Cloud computing, Optimization, Scheduling, Cloud Manufacturing and so forth. 